\title{
Partnering up in Q3
}

Stacy Lawrence

The potential value of partnership deals signed in Q307 hit \$10 billion, triple the total in Q207 and double that in Q306. A few deals in the $\$ 500$-million-plus range helped to drive these numbers. Stocks were also

\section{Biotech stock market performance}

Biotech indices are performing better, with the BioCentury 100 up 22\% and Nasdaq Biotech up 15\% since June 2006.

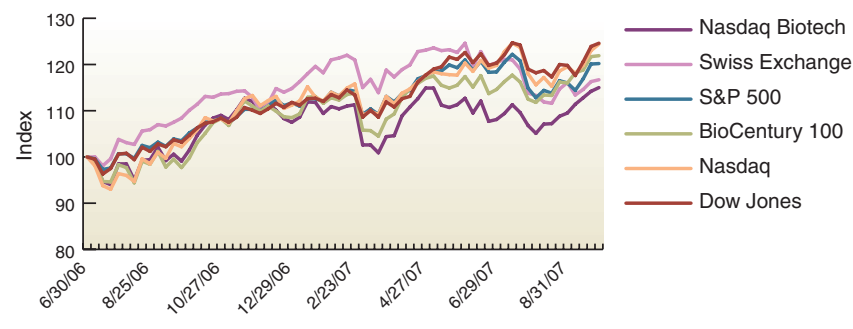

Source: $B C I Q$ : BioCentury Online Intelligence, Multex

\section{Global biotech initial public offerings}

China's WuXi (Shanghai), with its $\$ 168$ million NYSE offering, was the highlight of a mere four IPOs in Q3.

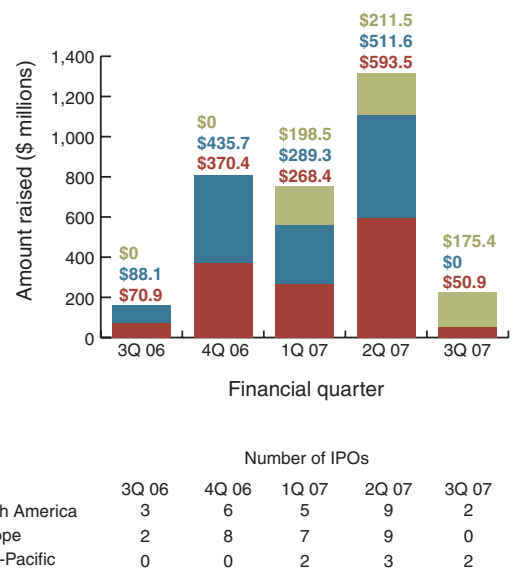

Asia-Pacific

Europe

- North America

Asia-Pacific

$\begin{array}{cc}0 & 2 \\ \text { Online } & \text { Intelligence }\end{array}$

Source: $\mathrm{BCIQ}$ : BioCentury Online Intelligence

\section{Global biotech venture capital investment}

VC funding continued at about $\$ 1.5$ billion or more, as it has in most recent quarters.

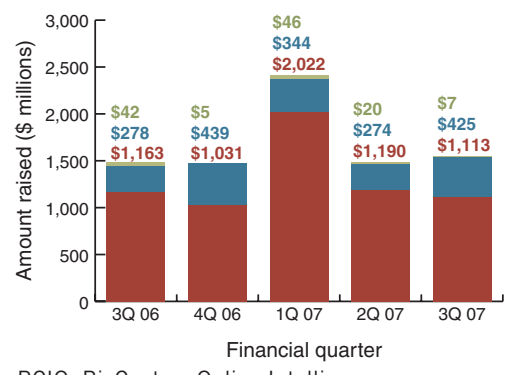

Asia-Pacific

Europe

- North America buoyant at the end of the third quarter. Venture capital (VC) investment in the area remains relatively constant. Market volatility, however, sank the initial public offering (IPO) market, which saw only a few issues.

\section{Global biotech industry financing}

A handful of large partnerships pushed the potential value of deals signed in $\mathrm{Q3}$ to $\$ 10$ billion.

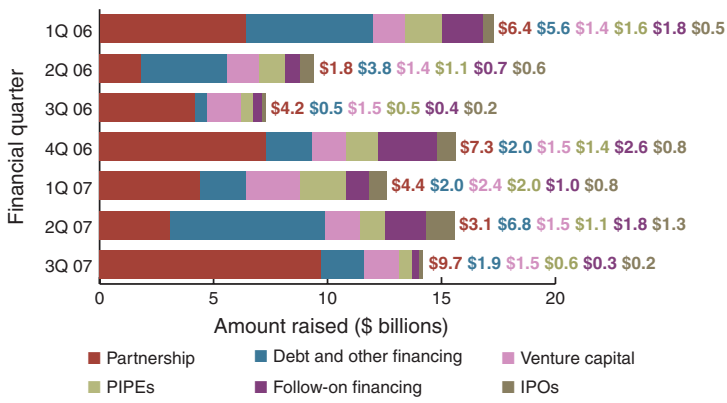

Partnership figures are for deals involving a US company. Source: BCIQ: BioCentury Online Intelligence, Burrill \& Company

Notable third-quarter biotech deals

IPOs

\begin{tabular}{|c|c|c|c|}
\hline $\begin{array}{l}\text { Company } \\
\text { (lead underwriters) }\end{array}$ & $\begin{array}{l}\text { Amount raised } \\
\text { (\$ millions) }\end{array}$ & $\begin{array}{l}\text { Percent change } \\
\text { in stock price } \\
\text { since offer }{ }^{1}\end{array}$ & Date launched \\
\hline $\begin{array}{l}\text { WuXi } \\
\text { (Credit Suisse, JP Morgan) }\end{array}$ & $\$ 168$ & $101 \%$ & 8-Aug \\
\hline Sucampo (Cowen) & $\$ 36$ & $-7 \%$ & 2-Aug \\
\hline \multicolumn{4}{|l|}{ Venture capital } \\
\hline Company & $\begin{array}{c}\text { Amount invested } \\
\text { (\$ millions) }\end{array}$ & Round number & Date closed \\
\hline Neuromed & $\$ 53$ & 5 & 21-Aug \\
\hline Ganymed & $\$ 52$ & 3 & 18-Sep \\
\hline Celator & $\$ 50$ & 2 & 2-Aug \\
\hline Nereus & $\$ 45$ & 4 & 9-Aug \\
\hline CureVac & $\$ 44$ & 2 & 10-Jul \\
\hline \multicolumn{4}{|l|}{ Mergers and acquisitions } \\
\hline Target & Acquirer & Value ( $\$$ millions) & Date announced \\
\hline Adnexus & Bristol-Myers & 505 & 24-Sep \\
\hline Esprit & Allergan & 370 & 19-Sep \\
\hline Novacardia & Merck & 360 & 25-Jul \\
\hline Evotec & Renovis & 152 & 18-Sep \\
\hline \multicolumn{4}{|l|}{ Licensing /collaboration } \\
\hline Researcher & Investor & Value (\$ millions) & Deal description \\
\hline Targacept & GlaxoSmithKline & 1535 & $\begin{array}{c}\text { Collaboration and } \\
\text { development }\end{array}$ \\
\hline Ariad & Merck & 727 & $\begin{array}{c}\text { Collaboration and } \\
\text { development }\end{array}$ \\
\hline Radius Health & Novartis & 500 & $\begin{array}{c}\text { Collaboration and } \\
\text { development }\end{array}$ \\
\hline SGX & Novartis & 490 & $\begin{array}{c}\text { Collaboration and } \\
\text { development }\end{array}$ \\
\hline
\end{tabular}

Stacy Lawrence is a Senior Writer at BioCentury 